\title{
Biochemical and technological characteristics of wooden breast chicken fillets and their consumer acceptance
}

\author{
Bruna Caroline Geronimo ${ }^{1}$ (D) Sandra Helena Prudencio ${ }^{1} \cdot$ Adriana Lourenço Soares $^{1}$
}

Revised: 21 April 2021 / Accepted: 27 April 2021/Published online: 7 May 2021

(C) Association of Food Scientists \& Technologists (India) 2021

\begin{abstract}
The wooden breast (WB) has caused great damages to meat producing industries, being its etiology still not fully understood. Thus, the objective of this work was to investigate biochemistry and technological characteristics of $W B$ chicken fillets and their consumer acceptance. $W B$ fillets were evaluated in regards to color, $\mathrm{pH}$, approximate chemical composition, water holding capacity, cooking loss, shear force, total and soluble collagen, and comparison estimated of pyridinoline. The sensorial analysis used real size images of fillets. The WB showed changes in physical parameters such as an increase in luminosity and shear force. In regards to the chemical parameters, showed an increase in $\mathrm{pH}$ value, moisture content, lipids, and mineral, and protein content reduction. There were biochemistry changes in the collagen with an increase of $17.32 \%$ in total collage content and a reduction by $30.96 \%$ in the estimated pyridinoline content. Technological parameters were negatively altered by a reduction in water holding capacity. $W B$ fillets showed a low acceptance rate and intention to purchase. Results show the $W B$ meat presented biochemistry and technological characteristics compromised besides a low acceptance and purchase intention, leading to economic losses for the poultry sector.
\end{abstract}

Keywords Sensorial analysis - Appearance - Collagen cross-links $\cdot$ Soluble collagen

Bruna Caroline Geronimo

bruna.geronimo@uel.br

1 Department of Food Science and Technology, State University of Londrina, P.O. Box 10.011, Londrina, PR, Brazil

\section{Introduction}

Wooden breast $(W B)$ is characterized essentially by palpable toughness, pale areas, caudal protuberance, and translucent fluid or citrin coloration on the surface (Sihvo et al. 2014), and, for these reasons, it is totally or partially condemned by the industry. These fillets, when processed, can also cause damages due to low yield (Petracci et al. 2015) and low water holding capacity (Mazzoni et al. 2015; Soglia et al. 2016; Geronimo et al. 2019). The low capacity of these fillets to retain water is associated with chemical alterations in protein and mineral content, with a simultaneous increase in moisture and lipids content (Sihvo et al. 2014; Mazzoni et al. 2015; Soglia et al. 2016; Geronimo et al. 2019). Changes associated with inflammatory processes and muscle fibers degeneration (Sihvo et al. 2014; Mazzoni et al. 2015; Soglia et al. 2016).

Although the etiology of this anomaly has not been fully explained, it is known that $W B$ fillets show fibrosis, with an accumulation of connective tissue and an increase in collagen deposition (Sihvo et al. 2014; Soglia et al. 2016), which can be related to the toughness found in these meats. However, the increase in natura meat toughness is related not only to collagen content, but also to the amount and stability of cross-links, being the pyridinoline the main form of cross-link found in collagen, characterized and identified for being a thermostable and permanent compound (Coró et al. 2002). As the concentration of pyridinoline increases, collagen solubility decreases, making meat texture tougher (Coró et al. 2002). Pyridinoline content in $W B$ fillets is still unknown.

Meat appearance, mainly color, is a determining factor for consumers, affecting directly their decisions about the quality and freshness of the cut (Damodaran et al. 2008). Color alterations, as the presence of pale and yellowish 
regions, and protuberances on the surface (Sihvo et al. 2014), may influence directly consumer's acceptance and purchase intention. Kato et al. (2019) investigated the perception of American and Brazilian consumers, respectively, in relation to the appearance of chicken fillets with white striping (WS), an anomaly that may occur simultaneously with $W B$. Both studies used photographic images during the evaluation and found out that, as the anomaly degree of severity increases, acceptance and purchasing intention decreases significantly. The main reason for rejection was associated with the presence of white stripes, which were associated with fat deposition on the surface. It should be noted that directional paired comparison tests in order to prove the paleness, consumer acceptance, and purchase intention have not yet been reported to $W B$ fillets.

Thus, the objective of this work was to investigate biochemistry and technological characteristics of $W B$ chicken fillets and their consumer acceptance. $W B$ fillets were evaluated in regards to color, $\mathrm{pH}$, approximate chemical composition, water holding capacity, cooking loss, shear force, total and soluble collagen, and comparison estimated of pyridinoline.

\section{Material and methods}

\section{Samples classification}

The study was conducted in a poultry slaughterhouse in Southern Brazil. Chicken from the same line (Ross 308 AP), mixed sexing, average weight and age ( $3.51 \mathrm{~kg}$ and 47 days) were selected and slaughtered, according to standard procedure, including electrically stunning, bleeding, scalding, deafeathering, evisceration, cooling, and deboning. Then, chicken breasts were classified and collected. Classification started from a visual and tactile inspection of the chicken breast fillets (Pectoralis major) in the slaughter line federal inspection area (or filleting) by trained specialists. Fillets with palpable toughness, pale areas, protuberance in the caudal region, according to the classification described by Sihvo et al. (2014) were considered as $W B$ $(\mathrm{n}=20)$. Normal fillets $-\mathrm{N}(\mathrm{n}=20)$ were classified based on their normal appearance, i.e., the visual absence of anomalies. After classification, full-size color photos $(1600 \times 1200$ pixels $)$ of the chicken fillets were individually acquired by an image acquisition system with of a standard illumination (Doc L-Pix model, Loccus Biotecnologia, São Paulo, Brazil), the coded fillets for further sensory analysis represented by digits 286 and 532 correspond to normal and $W B$, respectively (Fig. 1). The research was approved by the Committee on Ethics in the Use of Animals from Londrina State University (OF. CIRC. CEUA No. 10861.2018.12).
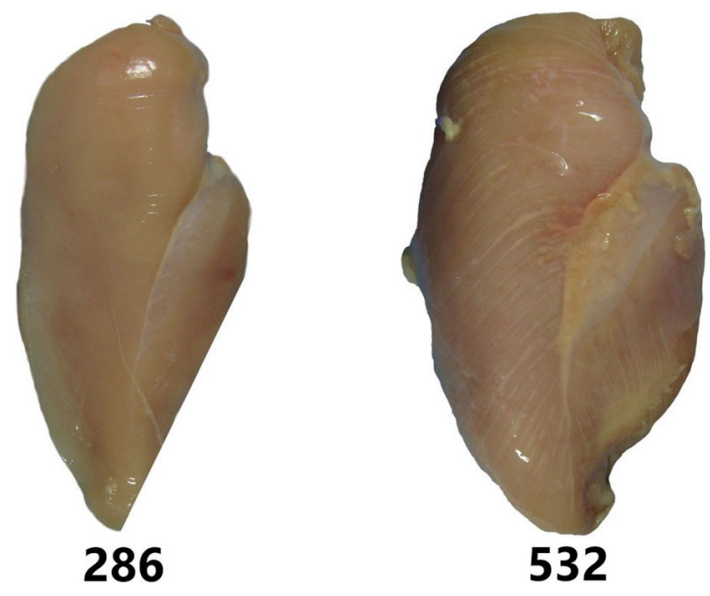

Fig. 1 Full-size color photos individually acquired from the normal chicken breast (286) and $W B$ (532) for sensory analysis

Chicken fillets were analyzed regarding their $\mathrm{pH}$ level, color $\left(\mathrm{L}^{*}, \mathrm{a}^{*} \mathrm{e} \mathrm{b}^{*}\right)$, approximate chemical composition, dimensions (cranial and caudal region height, width and length), water holding capacity (WHC), cooking loss (CL), shear force (SF), collagen content (total and soluble), comparison estimated of pyridinoline, directional paired comparison, and acceptance and purchase intention.

\section{Approximate chemical composition}

Approximate chemical composition was determined as described by AOAC (2005). Moisture was quantified by the oven-drying method at $105{ }^{\circ} \mathrm{C}$ until constant weight, ashes content by incineration in a muffle at $550{ }^{\circ} \mathrm{C}$, lipids by the Soxhlet method with petroleum ether after meat acid hydrolysis, and proteins by total nitrogen quantification by the Kjeldahl method, using a conversion factor of 6.25 .

\section{Color and $\mathrm{pH}$ measurement}

Color was measured $24 \mathrm{~h}$ post mortem with the help of a Minolta CR400 colorimeter with a D65 illuminant and results expressed by the CIELAB system (Soares et al. 2002). Readings were made at three distinct points of the internal and external regions of the chicken fillets to obtain values for $\mathrm{L}^{*}$ (luminosity), a* (green-red component) and $\mathrm{b}^{*}$ (blue-yellow component).

The $\mathrm{pH}$ value was also obtained $24 \mathrm{~h}$ post mortem from the insertion of a meat contact potentiometer electrode (Testo 205, Brazil) in the cranial ventral region of the fillet, as described by Olivo et al. (2001).

\section{Cooking loss}

The study used the method described by Honikel (1998) to quantify cooking loss (CL) using cuts from the cranial 
region of the chicken fillets $24 \mathrm{~h}$ post mortem, weighed previously and packed in plastic bags hermetically sealed. Next, samples were cooked in a water bath at $80{ }^{\circ} \mathrm{C}$ until reaching an internal temperature of $75{ }^{\circ} \mathrm{C}$. After the cooking, the exudate water was discarded and the samples were weighed again after reaching room temperature. The result was expressed in exudate water percentage, considering the initial and final mass of the fillets.

\section{Water holding capacity}

Water holding capacity (WHC) of the samples was determined $24 \mathrm{~h}$ post mortem as described by Hamm (1960). Previously weighed cubes of approximately $2.0 \mathrm{~g}$, originated from the cranial region were placed between a system with two paper filters and two acrylic plates. Next, after being pressed by $10 \mathrm{~kg}$ piece for $5 \mathrm{~min}$, they were weighed again. WHC was expressed in percentage, considering the samples initial and final mass.

\section{Shear force}

Shear force (SF) was conducted in raw and cooked samples, being the cooked samples the same submitted to the $\mathrm{CL}$ analysis. Samples were cut along the fibers in the dimensions of $1 \times 1 \times 2 \mathrm{~cm}$ (height, width, length) as described by Honikel (1998). SF was measured by a TAXT2i texturometer with a coupled Warner-Bratzler blade at a speed of $5.0 \mathrm{~mm} / \mathrm{s}$. Results were expressed in Newton $(\mathrm{N})$, corresponding to the force peak needed to shear the fibers transversally.

\section{Total and soluble collagen content quantification}

Total and soluble collagen content was determined as described by Woessner- Júnior (1961). $1.0 \mathrm{~g}$ of chushed sample with $15 \mathrm{~mL}$ of $\mathrm{HCl} 6 \mathrm{~mol} \mathrm{~L}^{-1}$ at $105{ }^{\circ} \mathrm{C}$ was hydrolyzed for $15 \mathrm{~h}$. The hydrolyzed was filtered, its $\mathrm{pH}$ adjusted to 6.0 to 7.0 with the addition of $33 \%$ of $\mathrm{NaOH}$

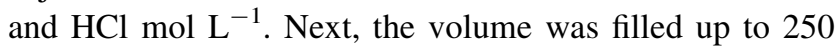
$\mathrm{mL}$ with distilled water. A $2.0 \mathrm{~mL}$ aliquot of the hydrolyzed sample was transferred to a test tube with $1.0 \mathrm{~mL}$ of chloramine solution maintained at rest for $20 \mathrm{~min}$ at room temperature. Soon after, $1.0 \mathrm{~mL}$ of $\mathrm{HCIO}_{4} 3.15 \mathrm{~mol} \mathrm{~L}^{-1}$ was added for an extra $1 \mathrm{~min}$. Next, $1.0 \mathrm{~mL}$ of dimethyl-4amino benzaldehyde, homogenized, and heated at $60{ }^{\circ} \mathrm{C}$ was added for $20 \mathrm{~min}$. Samples absorbance reading at 557 $\mathrm{nm}$ was conducted after they reached room temperature. Total collagen content was obtained from a standard curve with hydroxyproline and the total collagen content was calculated by the hydroxyproline content multiplied by 8.0 .

Soluble collagen content was determined according to the modified method of Oliveira et al. (1998). $2.5 \mathrm{~g}$ of sample was homogenized, using deionized water, for $1 \mathrm{~min}$ and heated at $80^{\circ} \mathrm{C}$. Next, samples homogenized by an Ultra Turrax at 22,000 rpm were centrifuged at $4000 \mathrm{rpm}$, for $15 \mathrm{~min}$. The supernatant was filtered $30 \mathrm{ml}$ of $\mathrm{HCl} 6$ mol L ${ }^{-1}$ was added for hydrolysis as described for total collagen determination.

\section{Comparison estimated of pyridinoline}

For collagen extraction, $10.0 \mathrm{~g}$ of samples were chopped and transferred to an erlenmeyer with $200 \mathrm{~mL}$ of $\mathrm{KCl} 0.6$ $\mathrm{mol} \mathrm{L}{ }^{-1}$ and kept under constant agitation for $24 \mathrm{~h}$ at $4{ }^{\circ} \mathrm{C}$. Next, samples were centrifuged at $1000 \mathrm{rpm}$ for $25 \mathrm{~min}$ at 4 ${ }^{\circ} \mathrm{C}$. The obtained precipitate was left submerged in water at $4{ }^{\circ} \mathrm{C}$ for $24 \mathrm{~h}$. Soon after, it was washed with $50 \mathrm{~mL}$ of distilled water at $4{ }^{\circ} \mathrm{C}$, homogenized and centrifuged. After the supernatant was discarded, the washing process was repeated 6 times (Lira et al. 1999). The obtained precipitate was freeze-dried and deep-frozen for $36 \mathrm{~h} .100 \mathrm{mg}$ of the freeze-dried sample were weighed and transferred to a screw-top test tube, added $1.0 \mathrm{~mL}$ of $\mathrm{HCl} 6 \mathrm{~mol} \mathrm{~L}^{-1}$ and sealed for posterior hydrolysis in an oven at $105^{\circ} \mathrm{C}$ for $24 \mathrm{~h}$ (Eyre et al. 1984).

The cellulose column was prepared according to Skinner (1982) and the mobile phase included 1-butanol, water and acetic acid (4:1:1). After the hydrolysis, the screw-top test tube received $0.5 \mathrm{~mL}$ of cellulose, $2.5 \%$ in the mobile phase, $0.5 \mathrm{~mL}$ of acetic acid and $2 \mathrm{~mL}$ of 1-butanol, homogenized and poured in the column. The column was washed three times with aliquots of $5.0 \mathrm{~mL}$ of mobile phase. For the extraction of the pyridinoline retained in the cellulose, 6.0 $\mathrm{mL}$ of ultrapure water was passed and collected. Next, it was centrifuged at 3000 for $8 \mathrm{~min}$ at $4{ }^{\circ} \mathrm{C}$. The supernatant phase was discarded and the remaining was frozen and lyophilized for $24 \mathrm{~h}$ for a comparison estimated of pyridinoline (Skinner 1982; Avery et al. 1996).

After lyophilization, samples $(n=20)$ were re-suspended in $1,0 \mathrm{~mL}$ of acetic acid $20 \%\left(\mathrm{v} \cdot \mathrm{v}^{-1}\right)$ for a spectrofluorimeter reading. Fluorescence detection intensity (in counts $/ \mathrm{mg}$ of insoluble collagen in $1.0 \mathrm{~g}$ dry sample) was determined by applying excitation of $297 \mathrm{~nm}$ and emission of $380 \mathrm{~nm}$ (Eyre 1987). The pyridinoline standard was not used as reference; however, the concentration could be estimated due to the isolation of the pyridinoline fraction used during the sample preparation, being, therefore, the majoritary pyridinoline fraction. The pyridinoline standard was not used as a reference; however, the concentration could be estimated due to the isolation of the pyridinoline fraction used during the sample preparation. The washing with $\mathrm{KCl}$, for example, aims to extract the myofibrillar proteins from the sample, soluble proteins, and all soluble content present in the sample, since pyridinoline is insoluble, thus eliminating possible interferences to the analysis. 

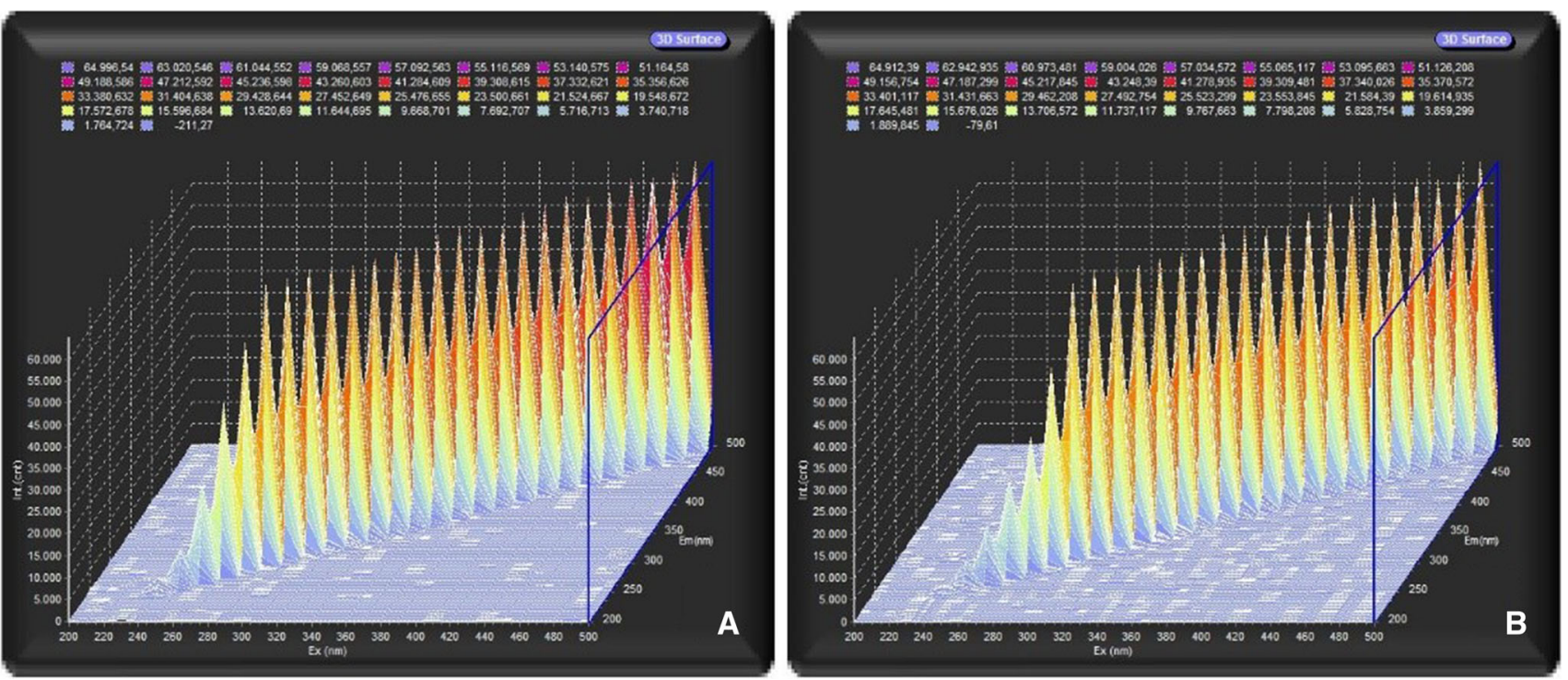

Fig. 2 Emission spectrum obtained from a normal fillet (a) and WB (b) for an estimated pyridinoline comparison

In addition, pyridinoline is a naturally fluorescent compound, being it possible to estimate its content from the spectrofluorimeter (CORÓ et al., 2002). In addition, Zhang et al. (2009) report that tryptophan residues, possible interferents, emit light at $340 \mathrm{~nm}$, not interfering with the wavelengths used in the analyses. The emission spectrum obtained for the normal (Fig. 2a) and WB (Fig. 2b) fillets indicates that both samples show the same behavior without fluorescent interferences, indicating the possibility of using it for an estimated comparison of pyridinoline content.

\section{Sensorial analysis}

The directional paired comparison, and acceptance and purchase intention tests were used to investigate the real impacts of the incidence of $W B$ in fillets destined to commercialization, applied at different days. To eliminate any possible bias, only habitual chicken meat consumers participated in the research. The study was approved by the Londrina State University Ethics Committee for Research Involving Human Beings no. 2.673.746, CAAE 89055118.9.0000.5231.

As recommended by the Ministry of Health, one of the emergency measures taken during the new coronavirus COVID-19 pandemic was to avoid agglomeration. The use of photos had already been proven as an effective method for the visual evaluation of raw chicken breasts, so the procedure was used during the white striping evaluation. (WS) (Kato et al. 2019).

The sensorial analysis was performed with 250 different and untrained panelists (chicken breast fillets consumers). The panel included $68.8 \%$ women and $31.2 \%$ men, predominantly between the ages of 26 and 35 (35.1\%) and consumption frequency of $1-3(74.1 \%)$ times a week. The photos codified with randomized numbers were presented simultaneously. The panelists were instructed to adjust the screen of their electronic instrument forming a $90^{\circ}$ angle for standardization purposes, and better image evaluation and color discrimination. Next, the directional paired comparison test was applied, with the request for the indication of the paler sample, followed by the acceptance test using the 9 points hedonic scale $(1=$ dislike extremely; $9=$ like extremely) and purchase intention using the 5 points structured scale $(1=\mathrm{I}$ definitely would buy to $5=\mathrm{I}$ definitely would not buy). At the end of each evaluation, panelists were asked the reason for their answers.

\section{Statistics analysis}

Directional paired comparison data were analyzed using a table based on the binomial distribution (one-tailed) according to Meilgaard et al. (1999). Overall acceptance results, purchase intention and physical, chemical and technological were evaluated using the Student $t$ test at 5\% of probability to compare $W B$ and Normal chicken fillets, using the Statistica 7.0 software.

\section{Results and discussion}

\section{Physical, chemical and technological parameters of WB fillets}

The incidence of $W B$ in chicken breast resulted in significant structural changes, compromising its physical, 
chemical, and technological characteristics. Chicken fillets with $W B$ showed higher $\mathrm{pH}$ value $(\mathrm{p}<0.05)$, results similar to those reported previously (Tasoniero et al. 2016; Geronimo et al. 2019; Madruga et al. 2019). The higher final $\mathrm{pH}$ value of chicken fillets was positively correlated with the increase in breast development, as described by Berri et al. (2007). In fact, fillets with $W B$ showed greater development, with an increase in the dimensions of the cranial and caudal regions, as shown in Table 1. This result can be due to a histological alteration caused by a muscle fibers degeneration, which reduces the glycogen content available, and consequently, reduces acidification during the post mortem period, reflecting in higher final $\mathrm{pH}$ value (Table 1) (Mudalal et al. 2014a; Sihvo et al. 2014). In addition, Abasht et al. (2016) observed in WB biomarkers associated with oxidative stress and alteration in the use of glycogen.

$W B$ fillets showed higher $\mathrm{L}^{*}$ and $\mathrm{b}^{*}$ values when compared to normal fillets (Table 1), confirming the presence of pale areas and yellowish regions in the cut, these alterations being microscopically observed in breasts with the anomaly (Sihvo et al. 2014). Moreover, this result may be related to the higher final $\mathrm{pH}$ value of $W B$ fillets and histological changes resulting from successive degeneration of muscle fibers (Petracci et al. 2015). Mudalal et al. (2014a), Tasoniero et al. (2016) and Geronimo et al. (2019) described similar results.

In regards to the fillets physical dimensions, $W B$ fillets showed a significant increase in the caudal and cranial region, with no significant alterations in width and length (Table 1). Results are in agreement with those reported by

Table 1 Physical, chemical and technological parameters in normal and $W B$ chicken fillets

\begin{tabular}{lrr}
\hline Parameters & \multicolumn{2}{l}{ Groups } \\
\cline { 2 - 3 } & \multicolumn{1}{l}{ Normal } & \multicolumn{1}{l}{$W B$} \\
\hline $\mathrm{pH}$ & $5.76^{\mathrm{b}} \pm 0.09$ & $5.88^{\mathrm{a}} \pm 0.12$ \\
$\mathrm{~L}^{*}$ & $52.79^{\mathrm{b}} \pm 2.68$ & $57.61^{\mathrm{a}} \pm 2.49$ \\
$\mathrm{a}^{*}$ & $-2.10^{\mathrm{a}} \pm 0.65$ & $-1.53^{\mathrm{b}} \pm 0.87$ \\
$\mathrm{~b}^{*}$ & $6.46^{\mathrm{b}} \pm 2.00$ & $7.84^{\mathrm{a}} \pm 2.06$ \\
Dimensions & & \\
Cranial region height $(\mathrm{cm})$ & $4.12^{\mathrm{b}} \pm 0.25$ & $5.13^{\mathrm{a}} \pm 0.32$ \\
Caudal region height $(\mathrm{cm})$ & $1.33^{\mathrm{b}} \pm 0.28$ & $2.49^{\mathrm{a}} \pm 0.34$ \\
Wigth (cm) & $9.32^{\mathrm{a}} \pm 0.94$ & $9.05^{\mathrm{a}} \pm 0.81$ \\
Length (cm) & $18.05^{\mathrm{a}} \pm 0.98$ & $17.70^{\mathrm{a}} \pm 2.01$ \\
WHC & $69.34^{\mathrm{a}} \pm 1.79$ & $67.87^{\mathrm{b}} \pm 2.40$ \\
CL & $21.29^{\mathrm{b}} \pm 1.37$ & $28.37^{\mathrm{a}} \pm 3.83$ \\
SF of raw (N) & $12.24^{\mathrm{b}} \pm 3.27$ & $19.59^{\mathrm{a}} \pm 5.40$ \\
SF of cooked (N) & $28.57^{\mathrm{a}} \pm 6.40$ & $28.26^{\mathrm{a}} \pm 5.53$ \\
\hline
\end{tabular}

WHC water holding capacity, $C L$ cooking loss, $S F$ shear force

${ }^{a . b}$ Different letters on the same line were statistically different according to Student's t- test $(p<0.05)$
Mudalal et al. (2014a) and confirm the protuberance in the caudal region and the bulging in the cranial region, alterations microscopically observed and that help detects the anomaly (Sihvo et al. 2014). In addition, these results suggest that chicken with $W B$ shows an increase in fillet development, supporting the hypothesis that the anomaly is correlated with the increase in the chicken growth rate (Mudalal et al. 2014a).

Raw $W B$ fillets were $37.52 \%$ tougher than the normal fillets by the shear force instrumental measure (Table 1), which is one of the main characteristics observed in the detection of the anomaly (Sihvo et al. 2014). The increase in the hardness of raw fillets can be explained due to the increase in collagen deposition resulting from the fibrosis process (Sihvo et al. 2014). However, the increase in hardness of the meat is not only related to the collagen content but with the amount of mature and stable crosslinking, the pyridinoline (Coró et al. 2002). In contrast, when cooked, there was no significant difference regarding hardness. This result may be directly related to the lower number of crosslinks observed in fillets with $W B$, as shown in Table 3. Results suggest that the muscle fiber regeneration process occurs an increase in collagen synthesis, with fewer crosslinks and immature formation of cross-links, which are easily broken by heating temperatures.

In relation to the technological characteristics, there was a reduction in water retention capacity in fillets with $W B$ and an increase in cooking loss (Table 1). These results are associated with the change in the chemical composition of the fillets with the anomaly, which showed a reduction in total protein content (Table 2), especially sarcoplasmic and myofibrillar proteins (actin and myosin) (Mudalal et al. 2014b), responsible for the water retention in the meat. This can be corroborated by the higher collagen: protein ratio (Table 3) and increased lipid content, inducing a high hydrophobicity, with a consequent reduction in its ability to water retention capacity in its structure (Soglia et al. 2016).

The $W B$ anomaly promoted alterations in the chemical composition of the meat (Table 2), with an increase by $2.43 \%$ in moisture that can be explained by the occurrence of a moderate to serious edema (liquid accumulation), a

Table 2 Approximate centesimal composition of normal and $W B$ fillets

\begin{tabular}{lrr}
\hline Parameters & \multicolumn{2}{l}{ Groups } \\
\cline { 2 - 3 } \cline { 2 - 2 } & \multicolumn{1}{l}{ Normal } & \multicolumn{1}{l}{$W B$} \\
\hline Moisture (\%) & $74.54^{\mathrm{b}} \pm 0.80$ & $76.40^{\mathrm{a}} \pm 1.21$ \\
Protein (\%) & $24.52^{\mathrm{a}} \pm 2.79$ & $20.85^{\mathrm{b}} \pm 1.35$ \\
Lipids (\%) & $0.69^{\mathrm{b}} \pm 0.16$ & $1.13^{\mathrm{a}} \pm 0.19$ \\
Ash (\%) & $1.15^{\mathrm{a}} \pm 0.06$ & $1.02^{\mathrm{b}} \pm 0.05$
\end{tabular}

${ }^{\mathrm{a}, \mathrm{b}}$ Different letters on the same line were statistically different according to Student's t-test $(p<0.05)$ 
Table 3 Total, soluble and pyridinoline collagen in normal and $W B$ chicken fillets

\begin{tabular}{lll}
\hline Parameters & \multicolumn{3}{l}{ Groups } \\
\cline { 2 - 3 } & Normal & $W B$ \\
\hline Total collagen $(\%)$ & $1.27^{\mathrm{b}} \pm 0.11$ & $1.49^{\mathrm{a}} \pm 0.20$ \\
Soluble collagen $(\%)$ & $0.16^{\mathrm{a}} \pm 0.03$ & $0.17^{\mathrm{a}} \pm 0.03$ \\
Collagen/protein ratio & $5.18^{\mathrm{b}}$ & $7.15^{\mathrm{a}}$ \\
Pyridinoline (counts/mg of insoluble collagen in $1.0 \mathrm{~g}$ dry sample) & $217.19^{\mathrm{a}} \pm 43.28$ & $149.96^{\mathrm{b}} \pm 27.11$
\end{tabular}

${ }^{\text {a.b }}$ Different letters on the same line were statistically different according to Student's t-test $(p<0.05)$ result of inflammatory processes (Sihvo et al. 2014). Fillets with $W B$ showed a reduction of $14.97 \%$ in protein content and an increase of $63.77 \%$ in lipids. The reduced protein content is due to the degeneration and atrophy of the muscle fibers (Mudalal et al. 2014b; Soglia et al. 2016), while the increase in lipids content is due to lipidosis, the replacement of the muscle tissues by adipose tissues (Sihvo et al. 2014; Velleman \& Clark 2015). In regards to ash content, fillets with $W B$ showed a reduction by $11.3 \%$, which could be due to the fibers degeneration process that causes damages to the membrane with consequential cell liquid losses and reduction of the present minerals, results similar to those reported by Mazzoni et al. (2015) e Geronimo et al. (2019).

\section{Changes in collagen biochemistry}

The collagen-protein ratio increase in the $W B$ fillets (Table 3) points out to a reduction in the nutritional value due to the collagen low digestibility and a deficiency in some essential amino acids (Mudalal et al. 2014b). WB fillets showed higher total collagen content by $17.32 \%$. The increase in lipids content parallel to the reduction in protein content was already observed previously by Mudalal et al. (2014b) when studying white striping (WS), an anomaly that also attacks chicken breasts and can also happen simultaneously to $W B$ (Tasoniero et al. 2016). According to Mudalal et al. (2014b) and Soglia et al. (2016), the degeneration and atrophy of the muscle fibers can induce a reduction in protein content, while, in the muscle degeneration process, there is a deposition of the conjunctive tissue, i.e., fibrosis, which, consequently, results in an increase in collagen content.

Collagen is a fibrous protein that has insolubility in water due to the high concentration and disposition of hydrophobic amino acids inside the molecule and on the surface (Damodaran et al. 2008). In meat, the increase in hardness is not only related to the collagen content, but to the quantity and stability of the cross-links, such as pyridinolines. In cross-linking, three collagen molecules are connected, making it more stable, insoluble and heat resistant (Damodaran et al. 2008). Soluble collagen is that solubilized during cooking, moreover, as the chicken ages, the solubility of collagen decreases, increasing the content of pyridinoline (Coró et al. 2002).

The pyridinoline corresponds to a naturally fluorescent trivalent amino acid that constitutes the collagen crosslink (Coró et al. 2002). Considering this natural fluorescence, the study used fluorescence spectroscopy for an estimated comparison of pyridinoline content. According to Eyre et al. (1984), a maximum excitation at $295 \mathrm{~nm}$ occurs in the $\mathrm{pH}$ acid due to the ring protonation of the hydroxyl group, while the maximum emission is observed at $395 \mathrm{~nm}$. Thus, samples readings were realized using these parameters.

Collagen cross-links are formed between individual molecules at highly specific points (Bailey 1992), and they increase with the muscular development and growth affecting meat quality, making it tougher (Coró et al. 2002). However, although fillets with $W B$ are characterized mainly by an increase in palpable rigidity (Table 1), there was a $30.9 \%$ reduction in pyridinoline concentration (Table 3). i.e., a lower number of collagen cross-links. This result may be due to successive processes that compromise the muscle fibers structurally, attested by the histological and physical-chemical evaluations (Sihvo et al. 2014; Soglia et al. 2016).

Histologically, fillets with $W B$ showed muscle fibers degeneration, reduction in the number of fibers, variation in fiber diameter, presence of atrophic fibers, mononuclear cells infiltration and interstitial inflammation (Sihvo et al. 2014). Sihvo et al. (2014) and Soglia et al. (2016) observed a process of degeneration and multifocal regeneration, multifocal necrosis, myopathic lesions, damaged muscle substitution by adipocytes, thickening of the perimysial network (fibrosis). Thus, the reduction of the estimated pyridinoline content in fillets with $W B$ may be due to these muscles lesions, since, despite the occurrence of these fibers regeneration, there is not enough time for the new biosynthetic collagen to develop mature pyridinoline cross-links.

\section{Directional paired comparison test, consumer acceptance and purchase intention of WB fillet}

The directional paired comparison test verified consumers' perception in relation to the pallor of chicken fillets with 
Table 4 Acceptance and purchase intention of normal chicken fillets and $W B$ through pictures taken individually

\begin{tabular}{lll}
\hline Degrees of $W B$ & Acceptance & Purchase intention \\
\hline Normal & $7.22^{\mathrm{a}} \pm 1.40$ & $4.37^{\mathrm{a}} \pm 0.89$ \\
$W B$ & $4.28^{\mathrm{b}} \pm 1.80$ & $2.60^{\mathrm{b}} \pm 1.15$ \\
\hline
\end{tabular}

$\overline{\mathrm{a}, \mathrm{b}}$ Different letters on the same column were statistically different according to Student's t-test $(p<0.05)$

WB destined to commercialization. An evaluation based on pictures taken individually, with standard lighting, excluded possible mistakes originating from external sources. From the 205 panelist, 103 identified the $W B$ as paler and 102 opted for the normal fillet. According to the one-sided test, there is no significant difference between normal chicken fillets and those with $W B$ in relation to paleness at the $5 \%$ probability level.

The use of pictures during the sensorial analysis has the sole purpose of evaluating the appearance of the product, which in this case, corresponds to chicken fillets sent to commercialization, since this is one of the main attributes altered in chicken with the anomaly (Sihvo et al. 2014; Geronimo et al. 2019). According to Table 4, chicken fillets with $W B$ showed a significant reduction in global acceptance $(40.72 \%)$, a result that affected directly and significantly the low purchase intention $(p<0.05)$. Considering that $64.4 \%$ of the consumers reported having slightly or strongly disliked chicken fillets with $W B$ and $56.6 \%$ of them certainly/possibly would not purchase the product. Therefore, although consumers saw no difference between the fillets in relation to paleness, $W B$ showed a low acceptance rate, and purchase intention was drastically reduced.

Consumers justified the reason for their answers in relation to the fillets both in the acceptance and purchase intention tests. The main problems mentioned for $W B$ were the strong presence of stripes, fatty aspect, tough meat appearance, difficult preparation, non-uniform color, and bulging. On the other hand, normal fillets had positive evaluations such as uniform size and coloration, healthy aspect, tender meat aspect and less fat. All observations indicate how much the consumer is aware of the variations in the standard of quality of chicken breasts, corroborating the results observed.

\section{Conclusion}

The incidence of the anomaly resulted in undesirable changes in the appearance and reduced technological quality of the chicken breast, compromising the yield and meat quality offered to the market or forwarded to the elaboration of processed products. In addition, fillets $W B$ showed a reduction in pyridinoline concentration i.e., a lower number of collagen cross-links. The anomaly compromised the perception of consumers, directly influencing a low acceptance rate and purchase intention, a result that may indicate economic losses for the poultry sector.

Acknowledgements The authors are grateful to the Coordination for the Improvement of Higher Education Personnel (CAPES) for granting a doctoral scholarship to Geronimo, BC-Finance Code 01.

Authors' contributions BCG and ALS planned the experiments. BCG carried out the experiments. All authors contributed to the interpretation and discussion of the results. BCG wrote the manuscript with input from all authors.

\section{Declarations}

Conflict of interest The authors declare that they do not have any conflict of interest of this manuscript entitled by "Biochemical and technological characteristics of wooden breast chicken fillets and their consumer acceptance".

Ethics approval The study was approved by the Londrina State University Ethics Committee for Research Involving Human Beings approved the study 2.673.746, CAAE 89055118.9.0000.5231.

\section{References}

Abasht B, Mutryn MF, Michalek RD, Lee WR (2016) Oxidative stress and metabolic perturbations in $W B$ disorder in chickens. PLoS ONE 11(4):e0153750. https://doi.org/10.1371/journal. pone. 0153750

AOAC, Association of Official Analytical Chemists. (2005), Official methods of analysis of AOAC, 18th edn. AOAC, Washington DC.

Avery NC, Sims TJ, Warkup C, Bailey AJ (1996) Collagen crosslinking in porcine $\mathrm{m}$. longissimus lumborum: absence of a relationship with variation in texture at pork weight. Meat Sci 42(3):355-369. https://doi.org/10.1016/0309-1740(95)00021-6

Bailey AJ (1992) Procter memorial lecture: collagen-nature's framework in the medical, food and leather industries. J Soc Leath Tech Ch 76:111-127

Berri C, Le Bihan-Duval E, Debut M, Santé-Lhoutellier V, Baéza E, Gigaud V, Jégo Y, Duclos MJ (2007) Consequence of muscle hypertrophy on characteristics of Pectoralis major muscle and breast meat quality of broiler chickens. J Anim Sci 85(8):2005-2011. https://doi.org/10.2527/jas.2006-398

Coró FAG, Youssef EY, Shimokomaki M (2002) Age related changes in poultry breast meat collagen pyridinoline and texture. J Food Biochem 26(6):533-554. https://doi.org/10.1111/j.1745-4514. 2002.tb00771.x

Damodaran S, Parkin KL, Fennema OR. (2008), Fennema's Food Chemistry. 4th edn. CRC Press, Boca Raton.

Eyre DR (1987) Collagen cross-linking amino acids. Methods Enzymol 144:115-139. https://doi.org/10.1016/00766879(87)44176-1

Eyre DR, Koob TJ, Van Ness KP (1984) Quantification of hidropiridinium crosslinks in collagen by high performance liquid chromatography. Anal Biochem 137:380-388

Geronimo BC, Mastelini SM, Carvalho RH, Júnior SB, Barbin DF, Shimokomaki M, Ida EI (2019) Computer vision system and near-infrared spectroscopy for identification and classification of chicken with $W B$, and physicochemical and technological 
characterization. Infrared Phys Technol 96:303-310. https://doi. org/10.1016/j.infrared.2018.11.036

Hamm R (1960) Biochemistry of meat hydration. Adv Food Res 10(2):355-463. https://doi.org/10.1016/S0065-2628(08)60141-X

Honikel KO (1998) Reference methods for the assessment of physical characteristics of meat. Meat Sci 49:447-457. https://doi.org/10. 1016/S0309-1740(98)00034-5

Kato T, Mastelini SM, Campos GFC, Barbon APAC, Prudencio SH, Shimokomaki M, Soares AL, Barbon S (2019) White striping degree assessment using computer vision system and consumer acceptance test. Asian-Australas J Anim Sci 32(7):1015-1026. https://doi.org/10.5713/ajas.18.0504

Lira GM, Shimokomaki M, Gioielli LA (1999) Efeitos do processamento sobre a solubilização das frações proteicas (miofibrilares e colagenosa) e textura da carne-de-sol. Rev Bras Ciênc Farm 35(2): 237-244

Madruga MS, Rocha TC, Carvalho LM, Sousa AMBL, Sousa Neto AC, Coutinho DG, Ferreira ASC, Soares AJ, Galvão MS, Ida EI, Estévez M (2019) The impaired quality of chicken affected by the wooden breast myopathy is counteracted in emulsion-type sausages. J Food Sci Technol 56(3):1380-1388. https://doi.org/ 10.1007/s13197-019-03612-0

Mazzoni M, Petracci M, Meluzzi A, Cavani C, Clavenzani P, Sirri F (2015) Relationship between pectoralis major muscle histology and quality traits of chicken meat. Poult Sci 94(1):123-130. https://doi.org/10.3382/ps/peu043

Meilgaard M, Civille GV, Carr BT (1999) Sensory evaluation techniques, 3rd edn. CRC Press, Boca Raton

Mudalal S, Babini E, Cavani C, Petracci M (2014a) Quantity and functionality of protein fractions in chicken breast fillets affected by white striping. Poult Sci 93(8):2108-2116. https://doi.org/10. 3382/ps.2014-03911

Mudalal S, Lorenzi M, Soglia F, Cavani C, Petracci M (2014b) Implications of white striping and $W B$ abnormalities on quality traits of raw and marinated chicken meat. Anim 9(4):728-734. https://doi.org/10.1017/S175173111400295X

Oliveira LB, Soares GJD, Antunes PL (1998) Influência da maturação de carne bovina na solubilidade do colágeno e perdas de peso por cozimento. Rev Bras Agrocienc 4:166-171. https://doi.org/10. 18539/cast.v4i3.217

Olivo R, Soares AL, Ida EI, Shimokomaki M (2001) Dietary vitamin $\mathrm{E}$ inhibits poultry PSE and improves meat funcional properties.
J Food Biochem 25:271-283. https://doi.org/10.1111/j.17454514.2001.tb00740.x

Petracci M, Mudalal S, Soglia F, Cavani C (2015) Meat quality in fast-growing broiler chickens. Worlds Poult Sci J 71(2):363-374. https://doi.org/10.1017/S0043933915000367

Sihvo HK, Immonen K, Puolanne E (2014) Myodegeneration with fibrosis and regeneration in the pectoralis major muscle of broilers. Vet Pathol 51(3):619-623. https://doi.org/10.1177/ 0300985813497488

Skinner SJM (1982) Rapid method for the purification of the elastin cross-links, desmosine and isodesmosine. J Chromatogr B Biomed Sci Appl 229(1):200-204. https://doi.org/10.1016/ S0378-4347(00)86052-1

Soares AL, Lara JAF, Ida EI, Guarnieri PD, Olivo R, Shimokomaki M (2002) Variation in the colour of brazilian broiler breast fillet. Proceedings Int Cong Meat Sci Technol 48(2):540-541

Soglia F, Mudalal S, Barbini E, Di Nunzio M, Mazzoni M, Sirri F, Cavani C, Petracci M (2016) Histology, composition, and quality traits of chicken Pectoralis major muscle affected by $W B$ abnormality. Poult Sci 95(3):651-659. https://doi.org/10.3382/ ps/pev353

Tasoniero G, Cullere M, Cecchinato M, Puolanne E, Dalle Zotte A (2016) Technological quality, mineral profile, and sensory attributes of broiler chicken breasts affected by white striping and $W B$ myopathies. Poult Sci 95(11):2707-2714. https://doi. org/10.3382/ps/pew215

Velleman SG, Clark DL (2015) Histopathologic and myogenic gene expression changes associated with $W B$ in broiler breast muscles. Avian Dis 59(3):410-418. https://doi.org/10.1637/11097042015-Reg.1

Woessner-Junior JF (1961) The determination of hydroxyproline in tissue and protein samples containing small proportions of this imino acid. Arch Biochem Biophys 93:440-447. https://doi.org/ 10.1016/0003-9861(61)90291-0

Zhang J, Liu W, Yi Z, Chen R, Li Y, Min Y (2009) The molecular mechanism of photodynamic therapy to fibrosis: regulation on the pyridinoline cross-link formation in collagen. Chin Sci Bull 54:2230-2234. https://doi.org/10.1007/s11434-009-0420-z

Publisher's Note Springer Nature remains neutral with regard to jurisdictional claims in published maps and institutional affiliations. 